\title{
EDITORIAL
}

\section{Business in the 1990s: Emerging opportunities for the OR practitioner}

The business world is undergoing rapid change as we enter the last decade of the 20th Century. PAUL THORNTON assesses the changes and outlines some of their implications and the opportunities for $O R$ in practice.

\section{Business in the 1990s}

The current debate about alternative futures for OR centres around two themes:

(1) extending OR's clientele to include, for example, community groups as well as business enterprises and government; and

(2) reappraising the role of the OR practitioner in adding value for clients, and the methodology and toolset to fulfil that role.

This debate is not fuelled by any immediate crisis in OR practice: indeed, many OR groups are experiencing greater demand than ever before. But there is a widelyheld view that much more needs to be done to ensure that OR realises its full potential, that it contributes to the major decisions, and that it does not become marginalized.

A comprehensive review of the current situation and its economic, social and educational dimensions is quite outside the scope of this article. However, it is clear that, however effectively we extend our client base (and I fully support the Society's efforts on this), the health of OR in practice will for the next several years be determined by its success within the business community (the more so under the present administration, since the private sector will be expected increasingly to fund activities within the educational and voluntary sectors).

My aim over the next few paragraphs is to try and identify some of the trends which will shape business in the 1990s, and the key issues which will occupy the minds of our commercial and industrial clients - issues which may provide opportunities for OR to become a more audible voice in the boardroom.

However, before turning to the future, it may be helpful to look briefly (and with horrendous oversimplification) at how the business landscape has changed over the 35 or so years of industrial OR application, and at how effective OR has been at addressing the issues of the day.

\section{5-1965}

The first few years after the Second World War were devoted to rebuilding shattered economies in many industrialized countries. By the mid-1950s, spending power and consumer demand were rising strongly, and for the next decade the challenge for most firms was that of maximizing output. This was a period of rapid development in the practical application of $O R$, and much of the work done made direct use of what are now regarded as classical OR techniques - linear programming, stock control, queueing theory, etc. There was an excellent fit between the pressing needs of most organizations for greater efficiency, better use of resources, higher productivity, etc., and the benefits which OR could deliver.

\section{5-1975}

This decade was very much the heyday of the corporate planner. As competition intensified, companies turned to new markets, diversification, vertical integration and international expansion. Most organizations were still managed centrally, with large head-office staffs, and their response to the growing complexity of business management was to develop improved systems for planning and control. Although the use of classical OR techniques waned during this period, OR was still very much at the centre of things, valued increasingly for the ability to harness management information and computer technology in the service of business planning. OR was involved more with the planning process than with the content of individual decisions. This time-frame also saw very rapid development in the numbers and standing of the business schools, and the rise of the MBA.

\section{5-1985}

Following the oil crises and the deterioration of business performance in the late 1970s, most major companies went in for some form of strategic reappraisal, characterized by:

(1) greater focus on core businesses and an end to diversification;

(2) delegation of responsibility to business units and arms-length relationships between businesses within the corporation;

(3) a more macho, less consultative style of management; and

(4) decimation of corporate/HQ staffs and the use of external rather than internal advisors.

These changes did not play to the strengths of OR, and many in-house groups settled for survival by making themselves indispensable in some worthwhile but unexciting aspect of the business, introducing PCs, doing the sales forecasting, etc. 
During this time, much of the high ground in management thinking was annexed by the business schools, at both analytical and cultural ends of the spectrum.

\section{Recent trends}

The past five years have seen a period of sustalned growth in the UK economy and, indeed, in the economies of most industrialized and industrializing nations. World trade has grown rapidly, and there has been a consistent spirlt of optimism within the business community, notwithstanding structural weaknesses in the economy as a whole.

OR has benefited from these developments and most groups are very heavily loaded, and experlencing problems in recruitment. Others are better able than I to assess the activities which dominate the workload of today's OR practltioners, but there is clearly great diversity (possibly too great, if we are viewed as brlght people with the ability to turn our hand to anything at short notice).

That said, I have an uncomfortable feeling that we ought to have had a much greater impact on management thinking in the late 1980s, in areas such as excellence, competitive advantage and total quality. It may be Inappropriate for OR to climb on any specific bandwagon, but there is surely much that could be done to take these concepts and to help to manage their implementation within our organizations in ways that ensure that the promised benefits are achieved.

\section{Major influences on the corporation}

So: how will business life look in the 1990s, and what issues will be at the top of the corporate agenda? Some work carried out recently within my own company highlighted the following major trends:

(1) shifts in the distribution of economic and political power, caused by the growing dominance of Japan and South East Asia, by Glasnost/ Perestroika and by the completion of the single European market;

(2) intensified international competition across all sectors of the economy as tariff and non-tariff barriers to international trade are dismantled;

(3) an acceleration in the pace of technological change, not only in IT but in areas such as biotechnology and application of new materials;

(4) increasing competition in the labour market as the

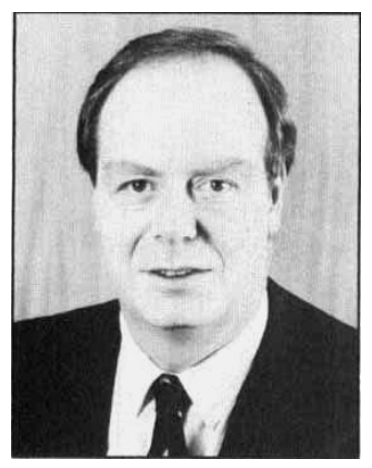

PAUL THORNTON is a Director of PA Consulting Group. He joined PA's Management Sciences Division in 1974 and was the Division's Director for five years before becoming Group Marketing Director in 1987. He is President-Elect of the OR Society. number of school and college leavers decline in most industrialized countries;

(5) continuing dlsengagement of the state from economic activity, and increasingly, the separation of regulatory, servlce provlslon and funding aspects of publlc services; and

(6) sustained and growing concern about all aspects of the environment, driven by consumers and legislators (Brussels, rather than Westminster).

\section{Opportunities for OR}

The Influences outllned above will have qulte differential impacts, depending on an organization's size, sector, maturity, etc. The question is whether there are any common themes around which $\mathrm{OR}$ endeavour can crystallize.

There appear to be at least four areas arising directly from these global trends which could be expected to provide nourishment for OR practitioners into the 1990s:

(1) the environment, and how to gain commercial benefits (with employees, regulators and the medla as well as with customers/consumers) through positive policies for environmental protection;

(2) development and implementation of winning strategies and tactics in global markets;

(3) all aspects of human resource management, including attractlng and retaining staff, increased automation and greater use of external services; and

(4) improving organizational responsiveness so that short-term opportunities can be capitalized upon quickly in a rapidly-changing world.

Whilst the first three of these are really not new and might be considered to be "owned" by other departments in most companies, the fourth area may, in some guise or other, become the hot button of the early 1990s. Certainly, the reactlon time of many of today's corporatlons is so long that they are continually exposed to attack from smaller, more responsive competitors. The challenge to the large corporation affects all aspects, including culture, systems, organization and external relationships. However, the prize, and also the cost of failure, may be enormous.

This may, of course, all be nonsense! Another oil crisis could change the picture altogether and throw us into another bout of cost-cutting; the trends outlined above may prove not to be slgnificant; or the OR community may have nothing to contribute. However, if we are to play a fulfilling role In corporate decision-making, then we must take the lead in helping our cllents to address thelr first-order problems - the problems that they lie awake at night worrying about. I would welcome the views of $O R$ Insight readers about what these problems are likely to be, and how they view the opportunities for OR. 